shock, in emergency while awaiting delivery of fully cross matched blood, 5 and as agents relieving both coronary ${ }^{6}$ and cerebral $^{7}$ ischaemia. Further experience seems likely to open up a new and potentially very valuable approach to the immediate management by paramedical personnel of large numbers of casualties from disasters or armed conflicts. The perfluorochemicals might also be used instead of blood for priming extracorporeal pumps and for perfusing organs before transplantation. ${ }^{8}$ They might be tailored to remain in the circulation for long enough to be of value in patients with thalassaemia major or aplastic anaemia without the present risks of hepatitis or of iron overload. They might have a place in the management of severe anaerobic infections. One thought provoking suggestion by Geyer ${ }^{2}$ is that they might be used in the targeting of malignant tumours for irradiation since the response is dependent on their oxygen content.

The list seems endless, for the emulsified perfluorochemicals have vast potential. To date they appear to be inert, non-toxic deliverers of dissolved oxygen to hypoxic tissue and of carbon dioxide to the lungs-a perfect present for the marathon runner. But first appearances may be deceptive, and, as Tremper and his colleagues suggest, ${ }^{4}$ their safety, as well as their efficacy, need to be shown in large scale clinical trials.

Peter M Jones

Consultant Paediatrician,

Newcastle Haemophilia Centre,

Royal Victoria Infirmary,

Newcastle upon Tyne NE1 4LP

' Yokoyama K, Suyama T, Naito R. Development of Fluosol-DA and its perspective as a blood substitute. In: Oxygen and life. Proceedings of the second Priestley conference. London: Royal Society of Chemistry, 1980:142-52. (Special Publication 39.)

- Geyer RP. Perfluorochemicals as oxygen transport agents in partial and total blood replacement. In: Oxygen and life. Proceedings of the second Priestley conference. London: Royal Society of Chemistry, 1980:132-41. (Special Publication 39.)

Clark LC, Gollan F. Survival of mammals breathing organic liquids equilibrated with oxygen at atmospheric pressure. Science 1966;152: 1755-6.

'Tremper KK, Friedman AE, Levine EM, Lapin R, Camarillo D. The preoperative treatment of severely anemic patients with a perfluorochemical oxygen-transport fluid, Fluosol-DA. N Engl f Med 1982;307: $277-83$.

Honda K, Hoshino S, Shoji M, et al. Clinical use of a blood substitute. N Engl f Med 1980;303:291-2.

${ }^{6}$ Glogar DH, Kloner RA, Muller J, Déboer LWV, Braunwald E, Clark LC Jr. Fluorocarbons reduce myocardial ischemic damage after coronary occlusion. Science $1981 ; 211: 1439-41$

${ }^{7}$ Peerless SJ, Ishikawa R, Hunter IG, Peerless MJ. Protective effect of Fluosol-DA in acute cerebral ischemia. Stroke 1981;12:558-63.

" Geyer RP. Fluorocarbon-polyol artificial blood substitutes. N Engl f Med $1973 ; 289: 1077-82$

\section{Alcohol and advice to the pregnant woman}

The adverse impact that a mother's drinking may have on the fetus was documented as long ago as 1899, when Dr William Sullivan published a report in the fournal of Mental Science showing that "female drunkards" incurred a stillbirth and infant mortality rate which was about two-and-a-half times greater than those in a comparison group. ${ }^{1}$ Those observations were, however, largely lost from sight until 1968, when French research workers described mental retardation and physical deformities among children born to alcoholic mothers. ${ }^{2}$ Somewhat later and independently an
American group ${ }^{3-5}$ provided a detailed clinical picture of the fetal alcohol syndrome as well as confirming the risks of higher neonatal and infant mortality. ${ }^{6}$

From these curious beginnings of discovery, neglect, rediscovery, and independent rediscovery, the research output has grown with overwhelming rapidity over the last decade, ${ }^{7}$ but fortunately several recent reviews give excellent summaries. ${ }^{8-20}$ The main impetus has come from the National Institute on Alcohol Abuse and Alcoholism (an American governmental agency), which has funded four major prospective studies of maternal drinking during pregnancy. ${ }^{21}$ Research on animals has also gone ahead rapidly. ${ }^{22}$ These initiatives in the United States provide a remarkable example of scientific energies being effectively directed towards a matter of public health concern and bears witness to the seriousness with which that country views its drinking problem. Some work on maternal drinking is now under way in Britain and other countries have made important contributions. ${ }^{12} 2223$

Among the mass of sometimes contradictory findings one conclusion stands out with certainty from the published data. The woman who continues to drink during pregnancy at a level deserving the clinical diagnosis of alcoholism is at severe risk of giving birth to a child who will manifest the fully developed triad of the fetal alcoholism syndromeretardation in growth, a cluster of characteristic dysmorphic features, and mental retardation. ${ }^{2}{ }^{4}$ The risk may be as high as $30 \%$. This syndrome can no longer credibly be claimed to be due to confounding variables such as smoking or poor maternal nutrition, though these may interact with the effect of alcohol. As well as the fully developed syndrome a range of more minor degrees and clusterings of fetal damage may occur. The evidence shows that a range of drinking patterns may combine with compounding factors and individual vulnerabilities to give rise to a wide spectrum of disorders. ${ }^{6}{ }^{13}$ The fetus is vulnerable at any stage of pregnancy. ${ }^{17}$ It is therefore insufficient to focus only on the extreme case. And, as already mentioned, the children of alcoholic mothers are also at risk of enhanced rates of stillbirth and infant mortality. ${ }^{6}$

So much for certain, but what is far more contentious is the relation between lesser and perhaps "social" degrees of maternal drinking and any type of harm to the fetus. As regards drinking and risk of spontaneous abortion, a recent prospective study of 32000 pregnancies in California suggested that among women taking one or two drinks daily the risk of abortion in the second trimester was double that for non-drinkers, ${ }^{24}$ while a study of 616 women from New York found an abortion rate of $25 \%$ among women who drank at least twice weekly, with a "minimal harmful dose" of two drinks on an occasion. ${ }^{25}$ Aspects of both these studies have been criticised, however; in particular, any self-report of drinking may be an underestimate. ${ }^{26}$

What about the effects of social levels of maternal drinking on fetal birth weight, the incidence of minor physical abnormalities, and subtle behavioural manifestations ?27-33 The Seattle group has reported a prospective study of 263 women which appears to show that an average intake of about two drinks a day can reduce birth weight, ${ }^{30}$ while a carefully controlled follow up of 500 women from the same group with "blind" assessment of the babies showed 19\% with congenital abnormalities when maternal drinking was at four or more drinks a day, $11 \%$ with mothers taking two to four drinks, and $2 \%$ abnormal children when maternal drinking was fewer than two drinks a day. ${ }^{32}$ Again, however, both the evidence and interpretations are open to criticisms, and 
Rosett has pointed out that the Seattle studies show that maternal age accounts for 10 times as much of the variance in developmental measures in the offspring as does maternal drinking. ${ }^{16}$

The present range in views on the riskiness of a mother drinking socially may be bracketed by two quotations from authoritative witnesses. On the one hand, Little ${ }^{12}$ writes that "the body of research relating moderate alcohol use to adverse fetal development is now too great and too consistent to discount ... drinking at levels that are generally considered within social norms is not safe for a developing child." Yet, on the other hand, Rosett ${ }^{15}$ argues that "No differences were found in frequency of abnormalities between offspring born to rare and moderate drinkers," and he goes on to say that "the danger from light drinking (less than $28 \mathrm{~g}$ absolute alcohol daily) has not been demonstrated and should not be overstated."

These differences in views should not, though, be exaggerated into a polarity. There is absolute consensus that a mother who is drinking "alcoholically" is putting her child in danger. There is also agreement that for some women lesser degrees of drinking may carry lesser but multiple risks. The debate centres on whether there is any minimal level of drinking which is free of risk or whether it is reasonable from present evidence to infer the likely existence of a dose response curve with the only safe lower limit being no drinking at all. The argument is one of degrees.

In these circumstances what are the appropriate health responses? The United States Surgeon General is sitting on no fences at all, and "advises women who are pregnant (or considering pregnancy) not to drink alcoholic beverages and to be aware of the alcoholic content of food and drugs." 34 Revising a previously more lenient statement ${ }^{35}$ which spoke only of the dangers of the fully developed syndrome, the Royal College of Psychiatrists recommends that "women would be well advised not to drink alcohol during pregnancy.",36

Alcohol problems notoriously attract absolutism, and covert moral stances easily become confused with medical advice. Threats to the unborn child excite particular anxiety. Lobbyists may seize on such an issue to manipulate support for a cause. Whatever the real biological problem, the story of the fetal alcohol syndrome might also profitably be studied in terms of what the sociologists would call the "social construction" of a problem. But, with all those provisos duly entered, the Surgeon General and the Royal College of Psychiatrists are giving no more than responsible and tempered public health advice which does not outrun the evidence: the premise is not that moderate drinking carries proved dangers to the fetus but only that the possibility of such dangers have to be entertained. The individual doctor has the responsibility of deciding what he will say to the expectant mother about her drinking, but questions on drinking must now be included in routine prenatal assessment. ${ }^{37}$ The alcoholic woman who is pregnant most certainly needs urgent and compassionate help. ${ }^{38-40}$

\section{GRIFFITH EDWARDS}

Professor of Addiction Behaviour,

Institute of Psychiatry,

London SE5 8AF

'Sullivan WC. A note on the influence of maternal inebriety on the offspring. f Ment Sci 1899;45:489-503.

"Lemoine P, Harousseau H, Borteru J-P, Menuet JC. Les enfants de parents alcooliques: anomalies observées à propos de 127 cas. Ouest Médical 1968;21:476-82.

${ }^{3}$ Ulleland C, Wennberg RP, Igo RP, Smith NJ. The offspring of alcoholic mothers. Pediatr Res 1970;4:474.
4 Jones KL, Smith DW. Recognition of the fetal alcohol syndrome in early infancy. Lancet 1973;ii:999-1001.

5 Jones KL, Smith DW, Ulleland CN, Streissguth AP. Pattern of malformation in offspring of chronic alcoholic mothers. Lancet 1973;i: 1267-71.

${ }^{6}$ Jones KL, Smith DW, Streissguth AP, Myrianthopoulos NC. Outcome in offspring of chronic alcoholic women. Lancet 1974;i:1076-8.

${ }^{7}$ Alcoholism and Drug Abuse Institute. Alcohol and pregnancy: a bibliography. Seattle: University of Washington, 1981. (Alcoholism and Drug Abuse Institute Technical Report, 81-91.)

${ }^{8}$ Anonymous. Fetal alcohol syndrome. Br Med $\mathcal{f} 1976$;ii :1404-5.

${ }^{9}$ Clarren SK, Smith DW. The fetal alcohol syndrome. $N$ Engl f Med 1978;298:1063-7.

${ }^{10}$ Clarren SK. Recognition of fetal alcohol syndrome. fAMA $1981 ; 245$ : 2436-9.

${ }^{11}$ Kessel N. The fetal alcohol syndrome from the public health standpoint. Health Trends 1977;9:96-9.

${ }_{12}^{12}$ Little RE. Epidemiologic and experimental studies in drinking and pregnancy: the state of the art. Neurobehav Toxicol Teratol 1981;3: 163-7.

${ }^{13}$ Little RE, Graham JM, Samson HH. Fetal alcohol effects in humans and animals. Advances in Alcohol and Substance Abuse 1982;1:3/4:103-25.

11 Little RE, Streissguth AP. Effects of alcohol in the fetus: impact and prevention. Can Med Assoc $\mathcal{F} 1981$; $125: 159-64$.

15 Rosett HL. A clinical perspective of the fetal alcohol syndrome. Alcoholism: Clinical and Experimental Research 1980;4:119-22.

${ }^{16}$ Rosett HL. The effects of alcohol on the fetus and offspring. In: Kalant OJ, ed. Alcohol and drug problems in women. New York: Plenum, 1980. (Research advances in alcohol and drug problems. Vol 5.)

${ }^{17}$ Rosett HL, Weiner L. Clinical and experimental perspectives on prevention of the fetal alcohol syndrome. Neurobehav Toxicol Teratol $1980 ; 2: 267-70$.

1* Streissguth AP, Landesman-Dwyer S, Martin JC, Smith DW. Teratogenic effects of alcohol in humans and laboratory animals. Science $1980 ; 209: 353-61$.

${ }^{19}$ Stimmel B. The sins of the mother: drug use during pregnancy. Advances in alcohol and substance abuse 1982;1:3/4:1-4.

${ }^{20}$ US Department of the Treasury and US Department of Health and Human Services. Report to the President and Congress on health hazurds associated with alcohol and methods to inform the general public of these hazards. Washington DC: US Government Printing Office, 1980.

${ }^{21}$ Rosett HL. Summary and recommendations: NIAAA prospective fetal alcohol studies. Neurobehav Toxicol Teratol 1981 ;3:243-5.

2.2 Prat O. Alcohol and the woman of childbearing age-a public health problem. Br F Addict 1981; 76 :383-90.

${ }^{23}$ Kaminski M, Rumeau-Rouquette C, Schwartz D. Consommation d'alcool chez les femmes enceintes et issue de la grossesse. Rev Epidemiol Med Soc Santé Publique 1976;24:27-40.

21 Olegård R, Sabel KG, Aronsson M, et al. Effects on the child of alcohol abuse during pregnancy. Retrospective and prospective studies. Acta Paediatr Scand 1979;275, suppl:112-21.

${ }^{25}$ Harlap S, Shiono PH. Alcohol, smoking, and incidence of spontaneous abortions in the first and second trimester. Lancet 1980;ii:173-6.

${ }^{26}$ Kline J, Shrout P, Stein Z, Susser M, Warburton D. Drinking during pregnancy and spontaneous abortion. Lancet 1980;ii:176-80.

${ }^{27}$ Anonymous. Fetal alcohol syndrome. Lancet $1976 ; \mathrm{i}: 1335$.

${ }^{28}$ Hanson JW, Streissguth AP, Smith DW. The effects of moderate alcohol consumption during pregnancy on fetal growth and morphogenesis. $\mathcal{7}$ Pediatr 1978;92:457-60.

${ }^{29} \mathrm{Kuzma} \mathrm{JW}$, Sokol RJ. Maternal drinking behaviour and decreased intrauterine growth. Alcoholism: Clinical and Experimental Research $1982 ; 6: 396-402$.

${ }^{30}$ Little RE. Moderate alcohol use during pregnancy and decreased infant birth weight. Am f Public Health 1977;67:1154-6.

${ }^{31}$ Streissguth AP, Barr HM, Martin DC, Herman CS. Effects of maternal alcohol, nicotine and caffeine use during pregnancy on infant mental and motor development at 8 months. Alcoholism: Clinical and Experimental Research 1980;4:152-64.

32. Streissguth AP, Martin DC, Martin JC, Barr HM. The Seattle longitudinal prospective study on alcohol and pregnancy. Neurobehav Toxicol Teratol 1981;3:223-33.

${ }^{33}$ Tennes K, Blackard C. Maternal alcohol consumption, birth weight, and minor physical anomalies. Am f Obstet Gynecol 1980;138:774-80.

${ }^{3.4}$ US Surgeon General. Surgeon General's advisory on alcohol and pregnancy. FDA Drug Bull 1981;11:9-10.

${ }^{35}$ Special Committee of the Royal College of Psychiatrists. Alcohol and alcoholism. London: Tavistock, 1979.

${ }^{36}$ Royal College of Psychiatrists. Alcohol and alcoholism. Bulletin of the Royal College of Psychiatrists 1982;6:69.

37 Weiner L, Rosett HL, Edelin KC. Behavioral evaluation of fetal alcohol education for physicians. Alcoholism: Clinical and Experimental Research $1982 ; 6: 230-5$.

${ }^{38}$ Little LE, Streissguth AP, Guzinski GM. Prevention of fetal alcohol syndrome: a model program. Alcoholism: Clinical and Experimental Research $1980 ; 4: 185-9$.

${ }^{39}$ Rosett HL, Oueliette EM, Weiner L, Owens E. Therapy of heavy drinking during pregnancy. Obstet Gynecol 1978;51:41-6.

" Rosett HL, Weiner L, Edelin KC. Strategies for prevention of fetal alcohol effects. Obstet Gynecol 1981;57:1-7. 